SciBX

\section{Translational biology with a clinical mindset}

\section{By Kai-Jye Lou, Staff Writer}

Attracted by INSERM's large network of labs and hospitals, MedImmune LLC has formed a strategic collaboration with the institute to explore translational biology and novel disease mechanisms with an eye to streamlining the flow of new discoveries into the clinic.

Under the three-year deal, MedImmune, the Institut National de la Santé et de la Recherche Médicale (INSERM) and the institute's INSERM Transfert S.A. tech transfer subsidiary initially will pursue 10 projects in the company's focus areas of cancer, respiratory disorders, inflammation and autoimmune diseases.

Bahija Jallal, EVP of R\&D at MedImmune, told SciBX the application of translational biology will help the company "hone in on the right patients earlier, which enables more focused drug development."

According to Jallal, "translational biology at MedImmune is focused on identifying patients with a particular set of characteristics that may benefit from various biological therapies."

For example, she said, "we may evaluate target overexpression, perform genotype analysis or gene expression profiling studies to help us segment the patient population, with the ultimate goal of identifying the right patient for the right drug at the right dose at the right time. In translational sciences we also simultaneously evaluate the utility of applying a biomarker approach to selecting the right patients for clinical trials."

Although MedImmune is the biologics unit of AstraZeneca plc, Jallal noted that "we work closely with colleagues at AstraZeneca, and any opportunity that may directly benefit both the small and large molecule portfolio will be explored and evaluated."

Future projects could cover additional disease areas. Ideas for new projects will primarily come from principal investigators at INSERM, who will turn the ideas into project proposals for review by a joint steering committee. A co-principal investigator at MedImmune may also work with the institute's principal investigator on this process.

Each party also has an alliance manager to facilitate understanding of partner intent, expectations and goals.

MedImmune will fund approved projects and will have first option to license IP generated from the collaboration for commercial purposes, according to Atul Saran, SVP of corporate development and ventures at the company.
"The scientists at INSERM will have the freedom to conduct their research, and MedImmune will have the freedom to develop and commercialize the results from these projects," said Jallal.

"MedImmune's areas of therapeutic focus and interest in target and drug discovery are very much aligned with the research interests of our own scientists," said Augustin Godard, head of licensing and strategic partnerships at INSERM Transfert. "Their scientists will have access to data on new disease targets and mechanisms identified by our scientists."

He added that the institute has access to a broad mix of patient data and samples as well as the corresponding animal models. "Thus, we can move back and forth from patient phenotypes to animal models in order to better understand the underlying mechanisms of a particular disease," he told SciBX.

At the same time, Jallal noted that many of the labs in INSERM's network are associated with hospitals, which should help streamline the translation of preclinical results into clinical-stage research.

INSERM has 316 research units, with $80 \%$ of them located at university hospitals. The institute also has 54 clinical investigation centers, which its researchers use to carry out clinical and health research projects.

Indeed, Godard suggested it could be possible to advance up to three compounds into clinical development within five years, based on the institute's track record on past collaborations.

Jallal noted that the approach being undertaken with INSERM is different from that of many of the company's other collaborations. Since AstraZeneca acquired MedImmune in 2007, the subsidiary has announced at least three $\mathrm{R} \& \mathrm{D}$ deals with biotechs and has in-licensed new compounds and technologies from at least seven other biotechs and one research institute.

The INSERM deal casts a wider net.

"Usually our scientists seek out specific technologies and principal investigators to work with, but this time we are collaborating with an entire institution and pursuing multiple disease areas," she told SciBX.

Godard said INSERM Transfert is looking to establish additional collaborations over the next year.

"Ideal partners for us would be those that are seeking a partner for innovative new target discovery as well as the corresponding early drug discovery based on our fundamental research, which are our areas of expertise," he said. "We could help a partner make a quick move into Phase I and Phase II trials with first-in-class molecules and good understanding of which patients to be treated, as we have a broad network of labs and hospitals and have access to many animal models."

Lou, K.-J. SciBX 4(17); doi:10.1038/scibx.2011.475

Published online April 28, 2011

COMPANIES AND INSTITUTIONS MENTIONED

AstraZeneca plc (LSE:AZN; NYSE:AZN), London, U.K.

INSERM Transfert S.A., Paris, France

Institut National de la Santé et de la Recherche Médicale, Paris, France

Medlmmune LLC, Gaithersburg, Md. 